\title{
UM POETA E UM POEMA ESQUECIDOS
}

\author{
José Américo Miranda \\ Universidade Federal de Minas Gerais
}

\section{O Poeta}

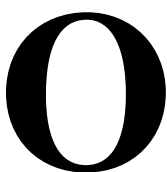

século XIX, para quem estuda a literatura de Minas Gerais, há de parecer um século paralítico, se comparado ao turbulento e glorioso século XVIII. Com as exceções de Bernardo Guimarães, hoje mais lembrado por sua ficção do que por sua poesia, e Alphonsus de Guimarães, poeta já do final do século, Minas Gerais parece ter contribuído relativamente pouco para a vida espiritual e o panorama literário do país. Entretanto, uma perspectiva pessimista como a que enunciamos não suporta um exame mais detalhado. Uma das causas dessa desproporção na avaliação da vida literária mineira dos dois séculos encontra-se no silêncio, no descaso e no desdém que o tempo presente tem manifestado com relação àquele período. Os poetas e escritores mineiros do século XIX não têm sido reeditados, não têm sido estudados, não têm sido lidos. Este artigo destina-se à lembrança de um deles: AnTônio Augusto de QueIroga.

Irmão de outro poeta, João Salomé Queiroga, Antônio Augusto de Queiroga nasceu na Vila do Príncipe, hoje cidade do Serro, em data que aguarda confirmação definitiva: 1811, segundo alguns autores, 1812 ou 1813, segundo outros. A trajetória poética de Antônio Augusto de Queiroga e sua fortuna editorial foram bem diversas das de seu irmão, embora ambos estejam hoje igualmente esquecidos e relegados a segundo plano. Ao passo que João Salomé Queiroga publicou, tardiamente, três obras (Canhenho de Poesias 
Brasileiras, em 1870; Maricota e o Padre Chico - lenda do Rio de S. Francisco, em 1871; e Arremedos, em 1873), o poeta Antônio Augusto, morto quando tinha cerca de 44 anos de idade, não chegou a publicar livros. Consta que era descuidado para com suas próprias composições, que não as recolhia e que era afamado repentista, tendo se dedicado à sátira.

Embora tenhamos hoje as três obras publicadas por João Salomé Queiroga, e nenhuma de seu irmão, Antônio Augusto atuou mais em seu tempo: foi um dos redatores da Revista da Sociedade Filomática, segundo informação de Raimundo Magalhães Júnior, foi o primeiro tradutor brasileiro de Byron. Além disso, foram incluídos poemas de Antônio Augusto de Queiroga nas principais e maiores antologias de poesia brasileira publicadas ao longo do século XIX. Não há poemas seus no Parnaso Brasileiro, de Januário da Cunha Barbosa, provavelmente, porque, àquela altura (por volta de 1830), ainda não estreara. Mas ele comparece nas páginas das seguintes antologias: Parnaso Brasileiro, de João Manuel Pereira da Silva (1843); Mosaico Poético, de Emílio Adet e Joaquim Norberto de Sousa Silva (1844); Florilégio da Poesia Brasileira, de Francisco Adolfo de Varnhagen (1853); e Parnaso Brasileiro, de Melo Morais Filho (1885). É curioso que de nenhuma dessas antologias constem poemas de seu irmão mais velho.

Antônio Augusto de Queiroga bacharelou-se em Direito pela Academia do Largo de São Francisco, em São Paulo, e exerceu a advocacia em Diamantina, segundo alguns autores, ou em sua cidade natal, conforme outros. A mesma dúvida paira sobre o local de sua morte, ocorrida em 1855. 


\section{O Poema}

\section{O SABIÁ}

LIRA

Tudo é silêncio no bosque!

Que solitária mansão!

Sabiá, cantando amores,

Só povoa a solidão,

Em débil ramo, saudoso

Descanta, geme e suspira.

Ah! Junta, cantor plumoso, Junta aos sons da minha lira Teu canto melodioso...

Tua música suave

É doce como a lembrança

Que em desabrida tormenta

Forma o nauta da bonança:

Dize, tu cantas zeloso?

Ou feliz amor te inspira?

Ah! Junta, cantor plumoso, Junta aos sons da minha lira Teu canto melodioso...

Livrem-te os céus do ciúme, Meu querido passarinho; E que a tua amante ingrata Te menospreze o carinho. Mas tu não cantas queixoso, Amor teus versos inspira.

Ah! Junta, cantor plumoso, Junta aos sons da minha lira Teu canto melodioso... 
Que acento que escuto agora!

Repete-o por piedade,

Alenta meu peito amante,

Mitiga minha saudade;

Esse nome harmonioso

De novo estes ares fira!

Ah! Junta, cantor plumoso, Junta aos sons da minha lira Teu canto melodioso...

Dize-o agora - oh! - não me ocultes

Quem meus amores te ensina,

Cantaste a beleza, as graças,

Pronunciaste Ocarlina;

Viste-lhe o rosto formoso,

Onde risonho amor gira!

Ah! Junta, cantor plumoso,

Junta aos sons da minha lira

Teu canto melodioso...

Ou viste-lhe o seu retrato

$\mathrm{Na}$ aurora purpúrea e bela?

$\mathrm{Na}$ rosa as faces mimosas,

Os olhos nalguma estrela?

Se a já viste, és desditoso,

Comigo em zelos delira!

Ah! Junta, cantor plumoso, Junta aos sons da minha lira

Teu canto melodioso...

Mas ai! A linda Ocarlina...

- Por que seu nome disseste? -

Não me atende, e a funda chaga

Abrir de novo quiseste!

Vi seu rosto gracioso...

E oh! nunca o rosto eu lhe vira!...

Ah! cessa, cantor plumoso,

Discorda dos sons da lira

Teu canto melodioso! 
Se estimas o teu descanso,

Não lhe repitas o nome;

Teme o fogo do ciúme,

Que este meu peito consome!

Vive em paz, dela te esquece,

Mas lembrem-te estes meus ais,

E chora os desgostos meus...

Ah! basta, não cantes mais,

Adeus, passarinho, adeus!

Esse poema, certamente o mais bem realizado de todos os que escreveu o poeta, aparece nas seguintes publicações: Parnaso Brasileiro, de João Manuel Pereira da Silva (1848); Florilégio da Poesia Brasileira, de Francisco Adolfo de Varnhagen (1853); e Parnaso Brasileiro, de Melo Morais Filho (1885). O poema é composto por nonas, todas em versos redondilhos maiores. Os três últimos versos da primeira estrofe funcionam como refrão, sendo repetidos ao final de cada uma das estrofes seguintes, até as duas últimas, nas quais aparecem modificados. Em todas as edições a repetição do refrão é apenas indicada por suas palavras iniciais ("Ah! Junta”) e um etc. Entendemos que esse procedimento é adequado para as grandes antologias, em que a questão da economia de espaço é premente, mas que seria inadequado editar o poema dessa forma nesta primeira edição do poema neste século. É preciso lembrar que, nas duas últimas estrofes do poema, em todas as edições, o refrão é modificado e, por isso, aparece impresso em sua totalidade. Na última estrofe o refrão fica reduzido a um dístico. No todo, o poema se compõe de oito estrofes de nove versos.

Em Pereira da Silva e em Varnhagen, o poema traz apenas a designação genérica de "Lira"; só em Melo Morais Filho aparece o título "O Sabiá", seguido pela indicação genérica ("Lira"). Entendemos que essa última forma é a mais adequada, porque dá ao poema um título que o especifica. Em 1885, quando Melo Morais Filho a publicou, a lira já tinha ganhado fama. Ela tinha-se tornado conhecida e era, segundo Fausto Cunha e Waltensir Dutra, dita "do Sabiá". O título, nesse caso, veio ao poema como testemunho de sua consagração. 
Na primeira estrofe, há uma discrepância, entre Pereira da Silva e Varnhagen, no que diz respeito à pontuação do sexto verso. Em Pereira da Silva, vem "Descanta, geme, e suspira.", e em Varnhagen, "Descanta, geme e suspira." Melo Morais Filho segue o exemplo de Varnhagen. A diferença entre os dois primeiros autores, separados por uma década apenas, parece nos indicar quando começaram a se introduzir os modos mais modernos de pontuação. A vírgula antecedendo a conjunção aditiva "e" era largamente utilizada no século passado. No caso desse verso, a intuição de Varnhagen o pontuou como o faríamos hoje. Entendemos, como Melo Morais Filho, que a conservou, que a lição de Varnhagen deve ser mantida.

Na segunda estrofe há outra divergência de pontuação entre os mesmos autores. Em Pereira da Silva o segundo verso traz vírgula no final; em Varnhagen e Melo Morais Filho falta a vírgula. Esse é outro uso freqüente, àquela altura do século XIX: a vírgula antes do pronome relativo "que", independente do tipo de oração introduzida por ele. No caso em pauta, o pronome introduz uma oração adjetiva restritiva, de modo que o uso da vírgula não é recomendado. Por essa razão, como Melo Morais Filho, adotamos a lição de Varnhagen. Nesta edição, ao final dessa estrofe, como no de todas as outras, repetimos integralmente o refrão, para que a forma do poema, em sua totalidade, possa ser melhor apreciada pelo leitor. Julgamos que, em não havendo necessidade de economizar espaço, o refrão deve ser repetido na íntegra.

A terceira estrofe apresenta uma ambigüidade que nos pareceu justificar uma intervenção, com a finalidade de explicá-la e esclarecêla. Eis a estrofe:

Livrem-te os céus do ciúme, Meu querido passarinho;

E que a tua amante ingrata

Te menospreze o carinho.

Mas tu não cantas queixoso, Amor teus versos inspira.

Ah! Junta , cantor plumoso, Junta aos sons da minha lira Teu canto melodioso... 
A consideração do poema em sua totalidade ajuda-nos a compreender melhor a estrofe. O poeta se encontra no bosque, sozinho, onde canta um sabiá. No refrão, o poeta pede ao passarinho que junte o seu canto (do passarinho) ao dele (poeta). Na segunda estrofe, o poeta indaga ao passarinho se ele "canta zeloso", se "feliz amor" o inspira. E nos dois versos finais da terceira estrofe (repetida acima) o poeta conclui que o passarinho, diferentemente dele próprio (poeta), não canta queixoso e que o amor lhe inspira os versos. A ambigüidade a que nos referimos encontra-se nos terceiro e quarto versos dessa estrofe; eles se coordenam aos dois primeiros por meio da conjunção "E", que dá início ao terceiro verso: "E que a tua amante ingrata / Te menospreze o carinho." Considerados fora de contexto, poderia parecer que o poeta está desejando ao passarinho que a amante dele (passarinho) lhe menospreze o carinho. Contudo, devemos lembrar que o primeiro verso começa por "Livrem-te os céus do ciúme" e que essas palavras ("Livrem-te os céus de") devem reger ainda os versos terceiro e quarto, de modo que devem estar subentendidas (por ocorrênica de zeugma) no terceiro verso, que deve ser compreendido assim: "E [livrem-te os céus de] que a tua amante ingrata / Te menospreze o carinho."

$\mathrm{Na}$ quarta estrofe, subitamente, o poeta julga ouvir, no canto do sabiá, o nome da mulher amada; ele pede ao passarinho que o repita. Essa estrofe é a mesma, em todas as edições do poema.

$\mathrm{Na}$ quinta estrofe, deparamo-nos com dois problemas. O primeiro verso, em Melo Morais Filho, traz a palavra "acultes" onde nas outras edições vinha "ocultes". A gralha nos pareceu evidente, pois a situação é justamente aquela em que o poeta pede ao passarinho que lhe (ao poeta) declare (que não lhe oculte) quem lhe ensinou (ao passarinho) os amores dele (poeta). No quarto verso, em que o poeta declara ter ouvido, no canto do passarinho, o nome da sua amada, a edição de Varnhagen traz o nome "Oscarlina”, e as outras edições "Ocarlina”. Optamos por esta segunda versão do nome em virtude dos seguintes fatos: 1. o nome "Ocarlina" aparece mais adiante, na sétima estrofe, grafado desse 
modo, no próprio Varnhagen; e 2. há, no Mosaico Poético, de Emílio Adet e Joaquim Norberto de Sousa Silva, um poema desse mesmo autor que tem por título "O Nome de Ocarlina".

$\mathrm{Na}$ sexta estrofe, o poeta continua indagando ao passarinho como e em que circunstâncias ele teria visto a sua amada. No primeiro verso há um cacófato pleno de significação: "Ou viste-lhe o seu retrato / Na aurora purpúrea e bela?" A alternativa apresentada pelo poeta ao passarinho, introduzida pela conjunção "ou" transforma, por razões fonológicas, o verbo "ver" em "ouvir"; o "ato falho" do poeta parece nos indicar sua aflição: ele deseja, desesperadamente, que, se o passarinho a viu (apelo ao sentido da visão), lhe diga (apelo à audição), imediatamente, como e onde. E conclui: "Se a já viste, és desditoso, / Comigo em zelos delira!"

Na sétima estrofe, o poeta se recorda de que sua amada o não quer ("Não me atende") e afirma preferir nunca ter-lhe visto o gracioso rosto. Seu sofrimento, que vinha num crescendo, ao longo do poema, atinge um grau extraordinário de intensidade, o que se expressa em alterações no refrão desta e da estrofe seguinte.

No refrão, alterado pela primeira vez nessa estrofe, deparamonos com três problemas. Para todos os casos houve solução, embora as implicações e reflexões provocadas por eles sejam radicalmente distintas. O primeiro verso do refrão ("Ah! cessa, cantor plumoso,") vem em Varnhagen sem a vírgula depois do verbo. Existe vírgula tanto na edição de Pereira da Silva como na de Melo Morais Filho, ou seja, tanto na edição que antecedeu a de Varnhagen como na que se lhe seguiu. Trata-se de um vocativo, o poeta se dirige ao passarinho, pedindo-lhe que cesse o canto; portanto, a ausência de vírgula em Varnhagen nos pareceu gralha. Adotamos a vírgula, como vem nas outras duas edições que teve o poema.

Um detalhe nos chamou a atenção nesse verso: depois do ponto de exclamação vem letra minúscula, onde no verso que vinha sendo repetido, de estrutura paralela à deste ("Ah! Junta, cantor plumoso,"), vem letra maiúscula. Entendemos que a mudança tem valor expressivo, que a dor intensificada do poeta encontrou 
expressão nessa fusão sintática entre a exclamação e o que ele pede agora ao passarinho: que cesse o seu canto. Nesse contexto, a ausência de vírgula, em Varnhagen, poderia também ser explicada pelo ímpeto exclamativo. Apesar dessa possibilidade interpretativa, conforme já mencionamos, adotamos a vírgula.

Por fim, o terceiro problema do refrão encontra-se no segundo verso, "Discorda dos sons da lira", que vem assim em Varnhagen: "Discorda os sons da lira". Há dois modos de entender o verso: um deles, com o verbo discordar no sentido de "não concordar", "divergir", é perfeitamente correto do ponto de vista métrico, dá sete sílabas ao verso sem a necessidade de artifícios na contagem delas. Nesse caso, o verbo está sendo utilizado no sentido que assumiu, de forma bem definida, em nosso século. O mais utilizado dicionário brasileiro da Língua Portuguesa, o Novo Dicionário da Lingua Portuguesa, de Aurélio Buarque de Holanda Ferreira, já não traz a outra significação, que o verbo tinha e que é o primeiro significado consignado para ele no Dicionário da Lingua Portuguesa, de Antônio de Morais Silva: o significado de "desentoar cantando" ou, simplesmente, como vem em Francisco Fernandes (Dicionário de Verbos e Regimes) e Caldas Aulete (Dicionário Contemporâneo da Lingua Portuguesa), "desafinar". Nesse caso, o verso adquiriria um sabor arcaizante, mais força expressiva e uma certa elegância no tocante ao sentido. Com esse entendimento o verso demandaria um artifício fônico que o enfraqueceria: a separação da última sílaba de "Discorda" do artigo definido, "os", que se segue ao verbo, no verso.

Parece-nos justificado lembrar que a lição de Varnhagen evoca uma tradição que remonta à lírica trovadoresca. Trata-se do tipo métrico do "descordo", em que contrastes da medida versificatória são utilizados, na expressão de Rodrigues Lapa, "para traduzir o desarrazoado pungente da paixão". Lido sob essa luz, o verso, na lição de Varnhagen, ganha ainda mais em riqueza expressiva. Deixa de existir, então, a necessidade de ajustar sua métrica à dos outros versos. Sua "disritmia" seria, pelo contrário, justamente, a expressão e o resultado do grau de exasperação em que se acha o poeta. 
Dados históricos, contudo, tendem a nos desautorizar essa leitura: trata-se do estado precário dos conhecimentos acerca da lírica trovadoresca ao tempo em que Antônio Augusto de Queiroga compôs o seu poema. Prevaleceu, portanto, na edição atual, a lição de Pereira da Silva, que foi seguida por Melo Morais Filho.

Enfim, na última estrofe, o sofrimento expresso pelo poeta atinge o seu grau máximo: o refrão, que era um terceto, reduz-se a dístico; a letra minúscula que se segue à exclamação ("Ah!") continua como na estrofe anterior; o poeta despacha o passarinho ("basta", "adeus, passarinho, adeus!"); e os versos, quase invariavelmente graves ao longo do todo o poema, tornam-se bruscamente agudos: "ais / meus / mais / adeus". O paroxismo de dor do poeta encontra nessas correspondências formais a sua expressão mais perfeita.

\section{Referências Bibliográficas}

ADET, Emílio, SILVA, Joaquim Norberto de Sousa. Mosaico poético. Rio de Janeiro: Berthe e Haring, 1844.

BLAKE, Sacramento. Dicionário bibliográfico brasileiro. Rio de Janeiro: Conselho Federal de Cultura, 1970. 7v.

DUTRA, Waltensir, CUNHA, Fausto. Biografia crítica das letras mineiras. Rio de Janeiro: Instituto Nacional do Livro, 1956.

ENCICLOPÉDIA de Literatura Brasileira. Rio de Janeiro: Fundação de Assistência ao Estudante, 1990. 2v.

LAPA, M. Rodrigues. Lições de literatura portuguesa: época medieval. s.l.: Coimbra, 1966.

MAGALHÃES JúNIOR, R. Poesia e vida de Álvares de Azevedo. São Paulo: Livros Irradiantes, 1971.

MENESES, Raimundo de. Dicionário literário brasileiro. Rio de Janeiro: Livros Técnicos e Científicos, 1978.

MORAIS FILHO, Melo. Parnaso brasileiro. Rio de Janeiro: B. L. Garnier, 1885. v.2. 
SILVA, J. M. Pereira da. Parnaso brasileiro. Rio de Janeiro: Eduardo e Henrique Laemmert, 1843-1848. 2v.

VARNHAGEN, Francisco Adolfo de. Florilégio da poesia brasileira. Rio de Janeiro: Academia Brasileira, 1946. 3v.

\section{Resumo}

Este artigo apresenta aos leitores atuais o poeta romântico mineiro Antônio Augusto de Queiroga, que o tempo relegou ao esquecimento. Um de seus poemas, a lira "O Sabiá", é também apresentado aos leitores. O poema é examinado com base nas edições que teve no século passado. O editor, comparando as diversas variantes do texto, tenta justificar suas escolhas, tecendo comentários e apontando possíveis interpretações.

\section{Abstract}

This article presents Antônio Augusto de Queiroga to actual readers. He is a forgotten romantic poet from Minas Gerais. One of his poems, the lyre "O Sabiá", is also presented. The poem is interpreted on the basis of the editions it has had in the last century. The editor, by comparing several text variants (versions), tries to justify his choices in the process of editing the poem. 